Military Technical College Kobry El-Kobba

Cairo, Egypt

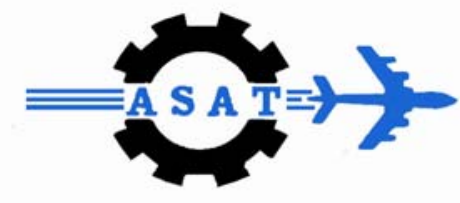

12-th International Conference

on

Aerospace Sciences \&

Aviation Technology

\title{
IMPACT DAMAGE EVALUATION OF FIBRE-REINFORCED COMPOSITE MATERIALS AND STRUCTURES
}

\author{
Jang-Kyo KIM*
}

\begin{abstract}
An overview is presented of destructive and nondestructive techniques that have been widely used to characterize impact damage in fibre reinforced composites. Particular emphasis is placed on in-depth study of the radiography and ultrasonic methods as the means of quantitative evaluation of internal damage in fibre composite structures. The operating principles of these techniques are described along with advantages and disadvantages in their applications. This paper highlights the chapter contributed by the author to the book.
\end{abstract}

\section{KEY WORDS}

Fibre reinforced composites; Impact damage; Characterisation; Non-destructive inspection; Ultrasonic C-scan

*Professor of Department of Mechanical Engineering, Hong Kong University of Science \& Technology, Clear Water Bay, Kowloon, Hong Kong (E-mail: mejkkim@ust.hk) 


\section{INTRODUCTION}

Damage in fibre reinforced composites can be caused by many different sources that include static and fatigue loading, low energy impact during the manufacture and in service, and environmental factors such as moisture absorption and corrosion. The low energy impact, in particular, can be potentially dangerous as it can produce extensive subsurface delaminations that are not visible on the laminate surface. It has been proven that the presence of internal damage causes substantial losses in strength and stiffness of the composite components $[1,2]$. The damage induced by low energy impact is a complex mixture of three principal failure modes, such as delaminations, transverse matrix cracking, fibre-matrix interface debonding and fibre fracture. The first two mechanisms are sensitive to the properties of the matrix material and the fibre-matrix interface, the third to the fibre failure strain [3].

To fully understand the damage state, not only must the surface damage be evaluated, but also the position and spatial geometry of all delaminations and transverse matrix cracks within the composite must be accurately identified. An accurate description of the impact damage state is a prerequisite to reliable assessment of residual mechanical properties. The importance of accurate damage assessment in fibre reinforced composites has lead to the developments of many techniques that can be classified into destructive and non-destructive means. Among the destructive techniques are the de-ply method and cross-sectional fractography both of which are designed to visualize the characteristic internal damage state. The non-destructive method involves detection, measurements of the size and locations of damage state based on optical microscopy, X-rays, ultrasonic, acoustic emission, laser optics, interferometry/shearography, thermal instruments, etc. There have been several excellent comprehensive reviews [4,5] that describe a wider range of measurement techniques for destructive and nondestructive evaluation of composite materials. Here, visual inspection, X-radiography and ultrasonic techniques are in-depth studied.

\section{VISUAL INSPECTION}

A great deal of information can be obtained by casting an eye over a composite structure. The visual inspection is particularly useful for moving components, such as helicopter rotor blades, turbine compressor buckets and water impellers. Periodic check of blade deflection can be used to monitor safe residual life, since the loss of strength is often accompanied by reduction in stiffness. Careful visual inspection can help identify the regions to be inspected by more sophisticated non-destructive methods. Reliability of visual inspection may be improved using conventional dye penetrants.

It was shown that visual inspection of glass fibre-thermoset matrix composites could reveal internal defects and damage. The reduction in transmission of light by delaminations can be accurately quantified using a solid state camera, whose image can be stored in a computer for the construction of digitised images. An optical microphotograph of a glass woven fabric vinyl ester matrix composite taken with the aid of transmitted light is shown in Fig. $1[6,7]$. In addition to the extensive delamination observed in the central impact area, minute interface debonding occurred along the warp and weft directions of woven fabric in the surrounding regions near the back surface of impact, which contributed considerably to the total damage area of the 
laminate. The total damage area varied significantly depending on the interfacial bond strength which was affected by silane coupling agent applied to the fibre surface.

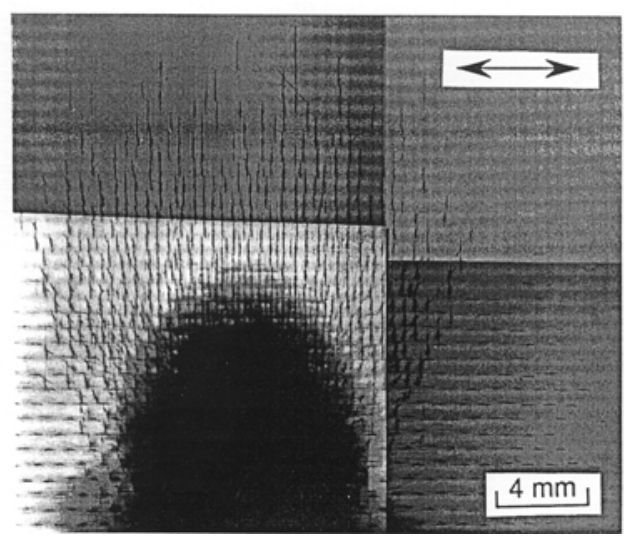

Fig. 1 A magnified view of impact damage in a glass fabric-vinyl ester matrix composite. After Hirai et al. [6].

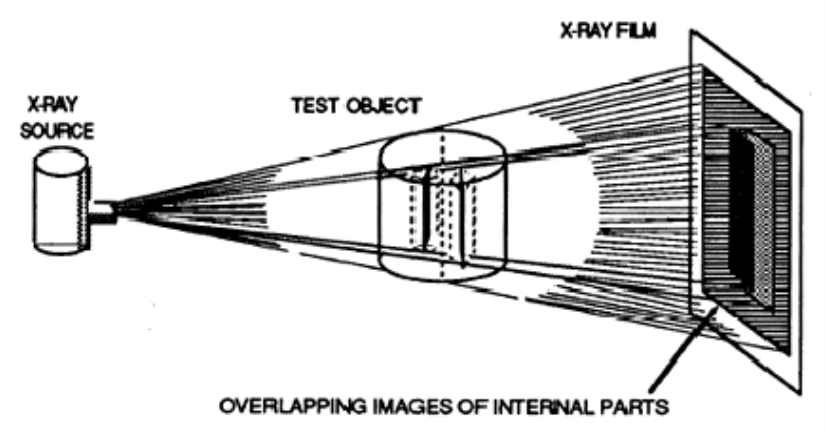

(a)

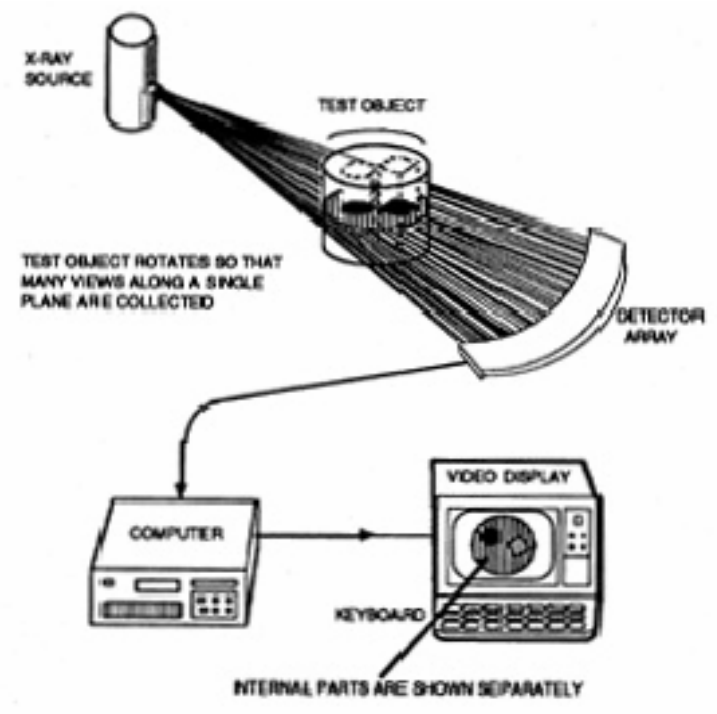

(b)

Fig. 2 Schematic diagrams comparing (a) conventional X-ray radiography and (b) X-ray computed tomography (CT).

\section{X-RADIOGRAPHY}

X-radiography is one of the most useful forms of NDE because it can be used effectively on very complicated structures. X-ray techniques have long proved complementary to other techniques in finding volumetric defects in composite materials. The $\mathrm{X}$-radiography relies on the differential absorption coefficient being directly related to material density and a function of the atomic number or scattering of X-ray photons as they pass through a material. The principle of radiography is schematically illustrated in Fig. 2. Significant progress has been made in recent years in developing X-ray imaging techniques without relying on films, achieving state-of-the-art methods, such as computed tomography (CT) and its variations. Unlike conventional radiography which 
produces a shadowgraph representing the attenuation experienced by the X-rays, the CT process utilises $X$-ray intensity measurements and computes an image of the specimen cross-section. The computed image is a highly accurate representation with a very fine resolution of the attenuation scale. The real time viewing of $X$-ray images can reduce the demand for X-ray films.

\section{De-ply and Stereo Radiography}

De-ply radiography involves a combination of standard radiography and the aforementioned de-ply technique. The laminate is first penetrated with a solution of zinc iodide and the resin is subsequently pyrolysed in a furnace, resulting in the separation of the individual layers. The radiographs of these laminae provide a 3D map of damage pattern. The series of radiographs in Fig. 3 [8] present the extent of notch tip damage in a $\left[0^{\circ} / 90^{\circ}\right]_{2 s}$ double-notched carbon fibre-epoxy matrix composite laminate after fatigue loading. The dark images of the photograph indicate the dye penetrant-filled cracks. The comparison of the radiographs taken before and after pyrolysis indicated that the resolution of the image was severely impaired by pyrolysis although the overall distribution of damage was visible after pyrolysis. This technique has a major limitation where each radiograph represents the sum of the image from both sides of an individual lamina.

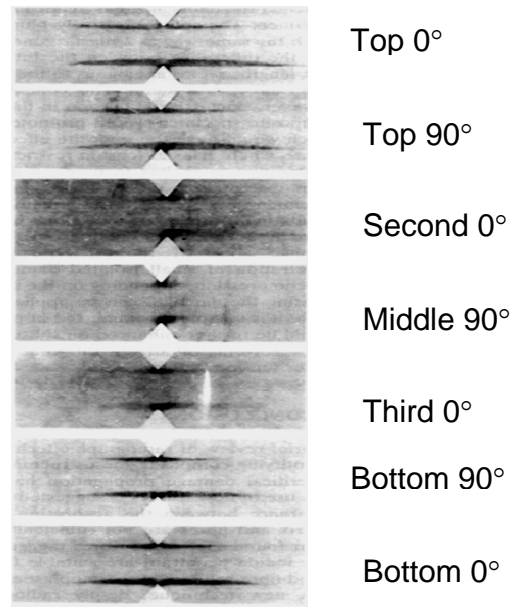

Fig. 3 De-ply X-radiographs of a $\left[0^{\circ} / 90^{\circ}\right]_{2 S}$ double-notched carbon fibre-epoxy matrix composite laminate after fatigue loading. After Kortschot and Zhang [8].

Stereo radiography is a simple technique where two X-ray photographs are taken of the same material at two different orientations to create an image from both the right and left eye perspectives. The two X-ray photographs are then combined together to visualize the damaged region in three-dimension with the aid of a stereo viewer or computer aided tomographic techniques. The depth of the delamination is determined relying on viewer's perception on natural depth, and the depth perception effect can be augmented by increasing the difference in the angles of inclination between the two radiographs.

\section{X-ray Computed Tomography (CT) and X-ray Tomographic Microscopy (XTM)}

The use of 'tomography' (literally meaning 'the picture of a slice') was pioneered in medical diagnostics where the systems are commonly known as 'computed tomography' (CT) [9]. The intensity of the X-rays is normally in the range of 60 to 100 
$\mathrm{KeV}$ for medical applications, while 100 to $650 \mathrm{KeV}$ is required for industrial applications. Combining the power of a computer with the traditional radiographic technique, the computed tomography (CT) is capable of reconstructing a 3D map from a finite number of radiographic images. The collimated $X$-ray beams go through the test object, which are received by a row of detectors placed opposite the $\mathrm{X}$-ray source (Fig. 4(b)). After the sample is rotated by a small angle, another two-dimensional absorption image is obtained. This process continues until $180^{\circ}$ of sample rotation have been recorded. The attenuation of the intensity of the X-ray beam is measured in a number of angular increments. Data acquisition is achieved by a computer that carries out reconstruction of the object with a suitable algorithm.

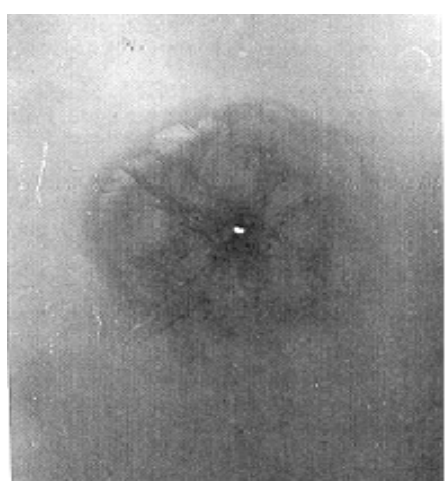

(a)

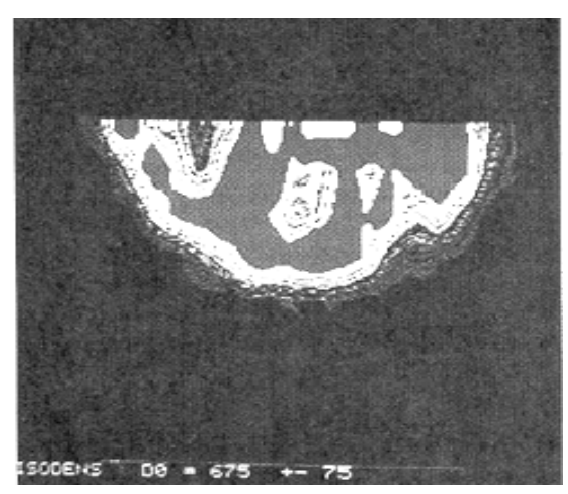

(b)

Fig. 4 Comparison of (a) conventional X-radiography and (b) computed tomography (CT) images of 28 layer quasi-isotropic carbon fibre-epoxy matrix composite laminate after impact. After Bathias and Cagnasso [10].

Major advantages of using X-ray CT techniques are good contrast sensitivity and high resolution. It was claimed that dimensional changes less than $0.01 \%$ and variations of density less than $0.1 \%$ could be detected, and the resolution of typical CT instruments for medical and industrial applications was as high as $25 \mu \mathrm{m}$. Although it is relatively difficult to provide enough resolution to detect tightly closed delaminations compared to ultrasonic C-scan techniques, the CT technique has been successfully applied to resolve composite defects, such as matrix cracks, delaminations and fibre bundles. Fig. 4 [10] suggests that a CT image alone provided much better resolution of the outline of the damage area than the planar view of X-radiography. Internal damage in a SiC fibre-reinforced aluminium matrix composite under static tension was also successful observed by the in situ X-ray CT technique based on a synchrotron radiation.

Based upon the same principle as the X-ray CT system, the X-ray tomographic microscopy (XTM) is equipped with a much greater volume resolution and faster data acquisition system. When focused high energy parallel X-rays are used from the radioactive sources, the spatial resolution can become better than $10 \mu \mathrm{m}$. The radiation source produces highly collimated X-ray beams that pass through a sample positioned on a rotation stage. They pass through a magnifying optical lens and are eventually converted into a visible light by means of a single crystal fluorescent scintillator screen. Lenses are used to alter the X-ray image formats in the electro-optic X-ray detector. The visible light image is recorded on a two-dimensional charge coupled device (CCD) detector. Tomographic software converts the X-ray 
absorption profile data into a two-dimensional construction of linear attenuation coefficients of the sample interior. In summary, both the X-ray CT and XTM techniques can provide a nondestructive means of evaluating impact damage and internal features of composite materials in both the qualitative and quantitative ways.

\section{ULTRASONIC TECHNIQUES}

Ultrasonic measurements are most commonly used to detect damage in composite structures. The basic principle of all these techniques is that ultrasonic pulses in the frequency range from 1 to $20 \mathrm{MHz}$ are generated to transmit through the material to a transducer (through-transmission mode) or to reflect back to the input transducer by defects or materials inhomogeneities (reflection or pulse-echo mode) [11]. In both techniques, a piezoelectric transducer is placed on one surface of specimen to introduce sound waves in the ultrasonic frequency range. As the sound waves propagate through the material, some of them are interrupted by the presence of defects or materials inhomogeneities, and the energy levels are attenuated. The amplitude, frequency dependence and arrival times of detected pulses are used for defect analysis. In the through-transmission mode where two transducers are used, the axes of the sending and receiving transducers must be perfectly aligned across the thickness of specimen for maximum efficiency.

A coupling medium with high acoustic impedance, e.g. de-ionised water, grease or gel, is needed between the transducer and the specimen to maximise the energy transfer. In a manufacturing operation, coupling to composites is usually achieved by immersing the specimen completely in a water tank. Immersion in water has an advantage over other coupling media in that the coupling remains uniform and thus the ultrasonic sound waves can be more focused and collimated. Coupling can also be obtained by squirting a narrow stream of water on the part surface, through which the ultrasonic wave is transmitted. It is well accepted that ultrasonic techniques are better suited to MMCs than to PMCs because ultrasound is rapidly attenuated by polymeric materials.

(a)

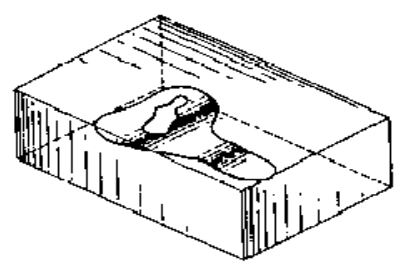

(b)

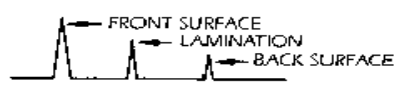

(c)

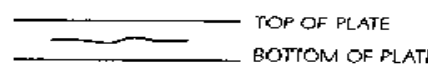

(d)

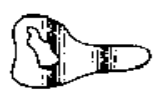

Fig. 5 Comparison of ultrasonic scanning techniques: (a) A specimen containing a delamination; (b) A-scan wave; (c) B-scan view; (d) planar view of C-scan. After Mclntire [11]. 


\section{Three Modes of Image Presentation}

Once the composite part is scanned at regular intervals across its surface, the ultrasonic map of defects can be presented in three different modes, namely A-scan, B-scan and C-scan, as shown in Fig. 5 [11]. In the A-scan mode, the attenuated signals are displayed as a series of peaks against the time scale on an oscilloscope. The position of its echo along the time axis allows the defect location to be detected in the thickness direction, while the amplitude of the echo can give some indication of the size and nature of the defect. In the B-scan analysis mode, cross-sectional measurement can be made along any vertical plane, eliminating the need for destructive cross-sectioning of specimen. B-scan is basically a series of very close-spaced A-scans through the thickness of specimen.

The well-established ultrasonic technique for composite structures is the C-scan mode where the extent of damage can be examined by varying the time gate. In the conventional C-scan analysis, the transducer is moved in a plane parallel to the specimen surface in a rectilinear raster pattern to provide a planar view of the defect in 'one shot' image. This image eliminates the need to produce multiple scans and is ideal for rapidly identifying gross anomalies in on-line inspection. High ultrasonic attenuation is shown in either dark grey or black colour in the C-scan image. Once the presence of a defect is identified on a C-scan, its location in the thickness direction can be obtained using the A-scan or B-scan analysis. Nevertheless, if there are several defects present at the same distance in the plane direction, but at different locations in the thickness direction, the ultrasonic waves may be attenuated by the first defect encountered and the other defects below it may not be clearly detected, due to the 'shielding effect' $[12,13]$.

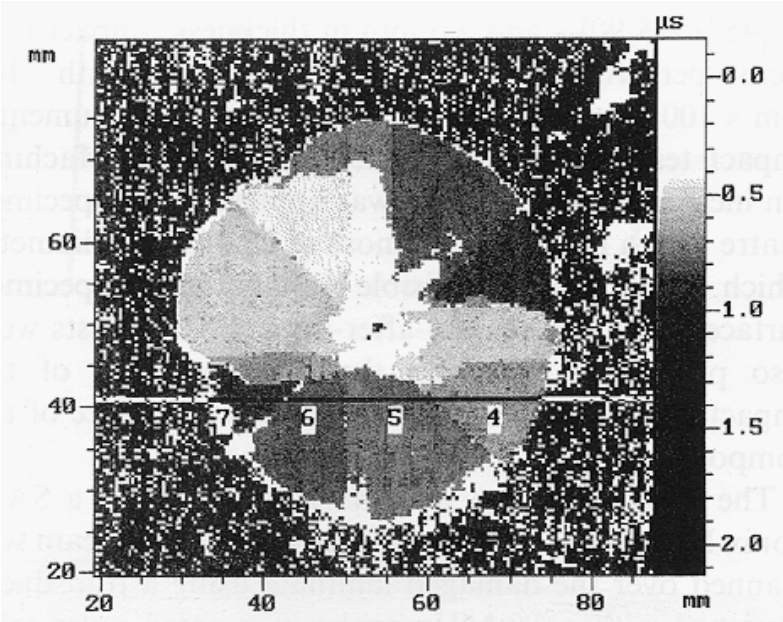

Fig. 6 SAM photograph of the gross impact damage in a 16 layer $\left[\left(-45^{\circ} / 0^{\circ} / 45^{\circ} / 90^{\circ}\right)_{2}\right] \mathrm{s}$ carbon fibre-bismaleimide (BMI) matrix composite. After Gao and Kim [5].

\section{Acoustic Microscopy Techniques}

A useful variant of conventional ultrasonic technique is acoustic microscopy. An acoustic microscope provides much higher sensitivity to critical impact damage than a C-scan. Two different types of acoustic microscopes are currently used: the scanning laser acoustic microscope (SLAM) and the scanning acoustic microscope (SAM). The SLAM is based on a through-transmission mode and operates at frequencies in the range of 10 to $500 \mathrm{MHz}$. A scanning laser detector is employed to generate real time 
images of internal features at a rate of about $1 / 30$ sec per image. In the SAM, the specimen is scanned line by line using a very fine ultrasonic beam. Two different types of acoustic wave modes are being used: the burst-wave and pulse-wave modes. In the pulse-wave mode, a specially designed lens is used to focus the ultrasonic waves onto a spot located at a depth up to 2-3 $\mathrm{mm}$ beneath the specimen surface. The reflected waves are received back from the spot, which are transmitted to a synchronous display to build up an image for the scanned area. SAM images can be generated for the cross sections (B-scan analysis), for the entire specimen thickness (multiple C-scans), or for specific depths (ply-by-ply C-scan analysis). The ply-by-ply C-scan analysis allows the damage accumulated through the thickness to be viewed by monitoring the ultrasonic signal amplitude at a specific specimen depth. Further, time-of-flight (TOF) analysis has been developed to allow the selection of narrow time gates and thereby to analyse the acquired 3D volume of data based on the travel time (i.e. time of flight) of reflected waves. Once the data are fixed with respect to the front and rear surface echoes, the information about travel time permits the internal damage to be identified. Therefore, in the TOF analysis, the internal features at any plane can be mapped topographically relative to the front surface or any sub-surface planes, resolving the distribution, size and shape of defects throughout whole specimen thickness, i.e. 'volume visualization' [5].

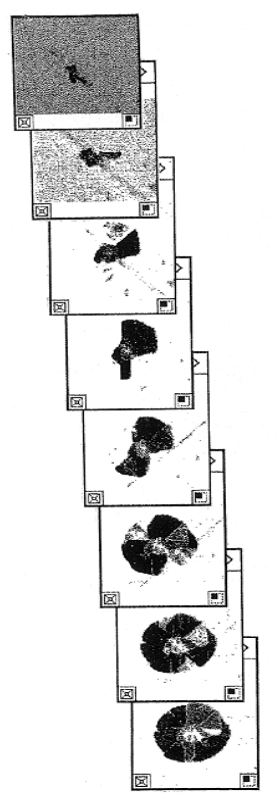

(a)

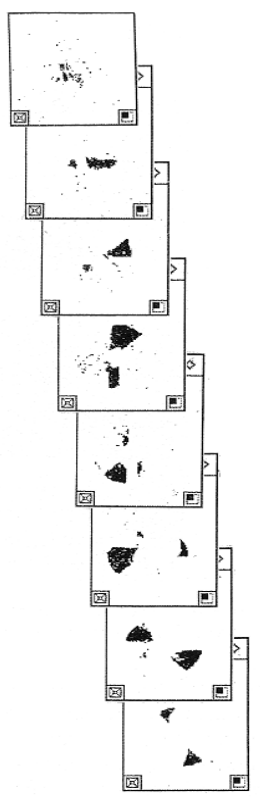

(b)

Fig. 7 SAM photographs taken from (a) ply-by-ply C-scan; (b) time-of-flight (TOF) analysis for the composite as in Fig. 6 [5].

The 3D distributions of impact damage in carbon fibre composite laminates containing several different types of thermosets and thermoplastics have been studied using SAM $[5,14,15]$. Fig. 6 illustrates a SAM photograph of the gross damage in a carbon fibre-bismaleimide (BMI) matrix composite obtained from the multiple C-scan. The total damage area had a circular shape, consistent with previous observations from conventional C-scan analysis for similar systems and lay-up sequence. The level of grey colour from light to dark grey indicates the depth of the layers containing such delaminations from the front surface. The SAM images of ply-by-ply C-scan and TOF analyses for the top eight layers are presented in Fig. 7. The former images provided 
information about accumulated damage toward the back surface, while the latter images allowed accurate measurements of damage area and shape at the individual layers.

The impact damage resistance of carbon fibre composite laminates as determined by several damage parameters was controlled by the type of matrix material and the processing condition [5]. Fig. 8 shows the SAM images generated from the TOF analysis of the impact damage in carbon fibre composites with epoxy and polyetheretherketone (PEEK) matrices. The reflected signals observed in the front and back several layers of the fast-cooled carbon-PEEK system did not represent damage, but were due to the high damping characteristics of PEEK. Fig. 9 presents the corresponding total delamination area and the residual strength plotted as a function of impact energy. The delamination area was small in the order of fast-cooled, slow-cooled carbon-PEEK and carbon-epoxy systems for a given impact energy level. Meanwhile, the incipient impact energy, $\mathrm{U}_{\mathrm{i}}$, below which no delamination occurred was low in the same order, indicating the impact damage resistance was superior in composites of the same order (Fig. 9 (a)). The ability to predict the residual strength of a damaged structure is of particular importance for an effective damage tolerant design. Impact damaged composites experience significant strength reduction $[16,17]$. The residual strengths were higher in the order of fast-cooled, slow-cooled carbon-PEEK and carbon-epoxy systems, although the absolute strength values were slightly higher for the slow-cooled composites than for the fast-cooled counterpart (Fig. 9(b)). The threshold impact energy, $\cup_{0}$, below which no strength degradation took place, was also highest for the fast-cooled carbon-PEEK system. All these observations indicates that the slow-cooled composites contained PEEK matrix with a high degree of crystallinity, giving rise to high strength and stiffness, whereas the relatively high ductility of amorphous-rich PEEK matrix in the fast-cooled composite enhanced the interlaminar fracture resistance.

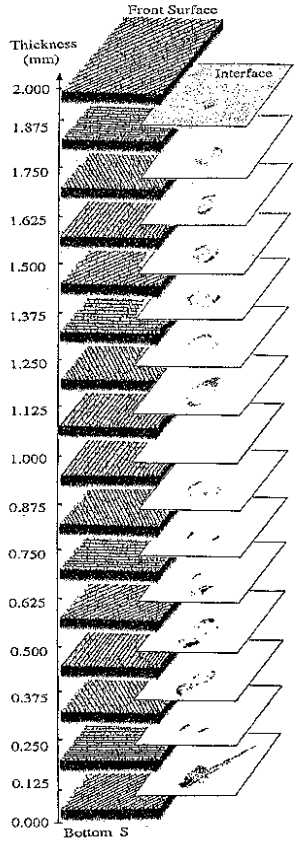

(a)

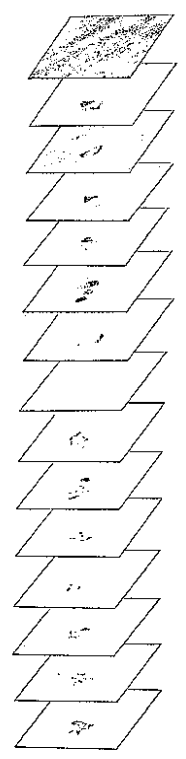

(b)

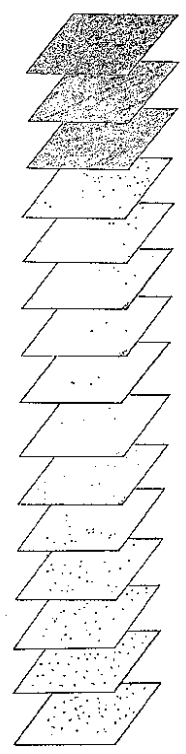

(c)

Fig. 8 SAM images obtained from the TOF analysis of the impact damage in quasi-isotropic (a) carbon-epoxy; (b) slow-cooled carbon-PEEK; (c) fast-cooled carbon-PEEK laminates at an impact energy of $12 \mathrm{~J}$. After Gao and Kim [14]. 
Apart from the foregoing discussion on characterisation of impact damage in composites, the SAM technique has also been widely used for applications in other types of fracture of composites. The SAM study of carbon fibre composite laminates containing epoxy and polyether-etherketone (PEEK) [14] revealed that the interlaminar crack fronts in mode I and mode II delamination fracture tests had a zigzag shape on the microscopic scale, while the front shape in mode I had a thumb-nail shape on the macroscopic scale. The delamination initiation was found to correlate well with the non-linear point in the corresponding load-displacement record. Interface debonding and surface opening cracks at the nitride-braze joint and gold-steel adhesive joint were also successfully detected using SAM.

(a)

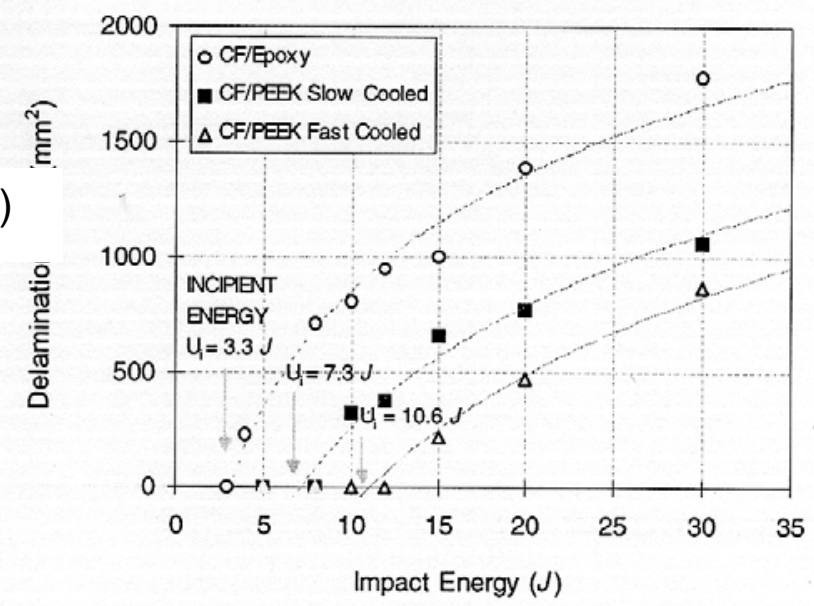

(b)

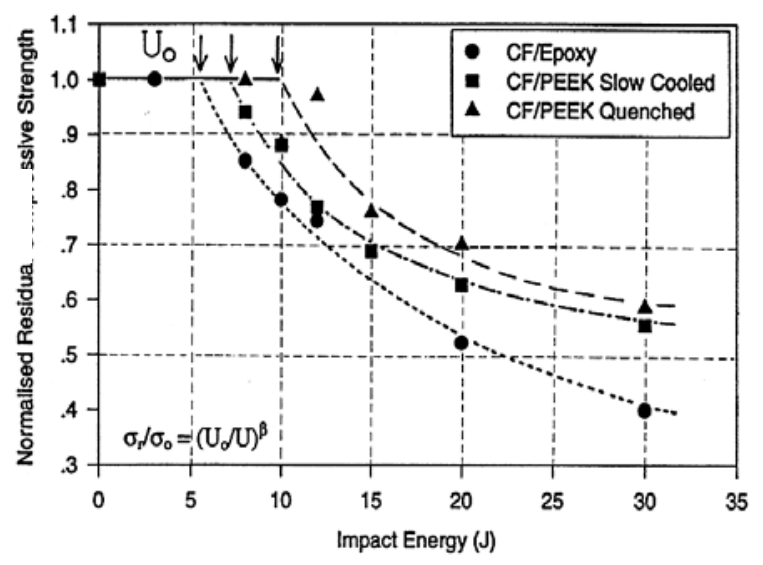

Fig. 9 (a) Total delamination area and (b) CAI residual compressive strength versus applied impact energy. The incipient impact energies, $U_{i}$, and the threshold impact energies, $\cup_{0}$, for three composites are indicated. After Gao and Kim [14].

In summary, the ultrasonic SAM techniques are a proven, powerful tool for reliable and accurate characterisation of impact-induced internal damage in composites. In particular, the combination of the ply-by-ply C-scan and TOF analysis is an efficient technique in 3D mapping of multi-layer delaminations, which in turn allows accurate measurements of delamination size and shape. Excellent correlation has been established with the results obtained from cross-sectional fractography. Nevertheless, the capabilities are still limited to the detection of damage whose characteristic 
dimensions are relatively large compared to the wavelength of ultrasound. Furthermore, the SAM techniques often fail to detect matrix cracks linking delaminations in the adjacent layers, and cannot provide accurate delamination patterns that are shielded partly or totally by the damage present in other layers, due to the 'shadow effect' [18].

\section{CONCLUDING REMARKS}

A great deal of experimental techniques have been developed and successfully employed to evaluate the damage state in fibre reinforced composites subjected to impact loading. The advancement in understanding the damage modes and failure mechanisms upon impact has been possible with the development of state-of-the-arts techniques, such as scanning acoustic microscopy (SAM) and X-ray tomographic microscopy (XTM). It is clear that the volume-visualization SAM combined with ply-by-ply and time-of-flight (TOF) analyses has been the method of first choice for impact damage characterization of composite laminates from both the detectability and image resolution viewpoints. The SAM indeed provides an effective and quick alternative to destructive, time-consuming de-ply and cross-section fractography techniques, capable of identifying damage shape, size and locations in three-dimensional perspectives. Radiography of various natures provide some capabilities complementary to SAM and other techniques based on ultrasound. The X-ray computed tomography (CT) and XTM have a great potential for 3D evaluation of damage in composites. As sensors, optical fibres embedded within the composite have the ability to detect the occurrence and location of delaminations. The other techniques, including acoustic emission, laser optical methods and infrared thermal methods, currently have limited capabilities in damage detection and image processing, compared to the SAM and XTM. Table 1 [5] summarizes the applicability and sensitivity of damage detection by various destructive and non-destructive inspection techniques. The technology to evaluate the damage or defects in composite materials is becoming mature, although none of the aforementioned techniques is perfectly ideal for obtaining all necessary information in desired conditions and locations. With the increasing applications of composites materials in many different industries, the demand for advanced instrumentation for damage detection and imaging techniques will be ever increasing.

Table 1 Rating of major inspection techniques with respect to impact damage sensitivity

\begin{tabular}{|c|c|c|c|c|c|c|c|c|}
\hline Factor or consideration & $\begin{array}{l}\text { De-ply } \\
\text { technique }\end{array}$ & Fractography & $\begin{array}{l}\text { Visual } \\
\text { inspection }\end{array}$ & $\begin{array}{l}\text { Scanning } \\
\text { acoustic } \\
\text { microscopy }\end{array}$ & $\begin{array}{l}\text { X-ray } \\
\text { tomographic } \\
\text { microscopy }\end{array}$ & $\begin{array}{l}\text { Thermal } \\
\text { imaging }\end{array}$ & $\begin{array}{l}\text { Acoustic } \\
\text { emission }\end{array}$ & $\begin{array}{l}\text { Laser } \\
\text { holography }\end{array}$ \\
\hline $\begin{array}{l}\text { Damage type sensitivity } \\
\text { Delaminations } \\
\text { Fibre breakage } \\
\text { Matrix cracks } \\
\text { Surface defects }\end{array}$ & $\begin{array}{l}\text { Good } \\
\text { Fair } \\
\text { Fair } \\
\text { Good }\end{array}$ & $\begin{array}{l}\text { Very good } \\
\text { Good } \\
\text { Fair } \\
\text { Good }\end{array}$ & $\begin{array}{l}\text { Good } \\
\text { Fair } \\
\text { Fair } \\
\text { Very good }\end{array}$ & $\begin{array}{l}\text { Good } \\
\text { Very poor } \\
\text { Very poor } \\
\text { Poor }\end{array}$ & $\begin{array}{l}\text { Fair } \\
\text { Good } \\
\text { Good } \\
\text { None }\end{array}$ & $\begin{array}{l}\text { Fair } \\
\text { Poor } \\
\text { Poor } \\
\text { Poor }\end{array}$ & $\begin{array}{l}\text { Poor } \\
\text { Poor } \\
\text { Poor } \\
\text { Very poor }\end{array}$ & $\begin{array}{l}\text { Fair } \\
\text { Poor } \\
\text { Poor } \\
\text { Poor }\end{array}$ \\
\hline $\begin{array}{l}\text { Damage size sensitivity } \\
\text { Damage location sensitivity }\end{array}$ & Good & Good & Fair & Good & Good & Fair & Very poor & Poor \\
\hline Distance from surface & Good & Very good & Fair & Good & Good & Poor & Very poor & Very poor \\
\hline
\end{tabular}




\section{REFERENCES}

[1] Kim JK, "Recent developments in impact damage assessment of fibre composites" in Impact Behaviour of Fibre-reinforced Composite Materials and Structures Chapter 2 (S. Reid and G. Zhou eds.) Woodhead Publishing, Cambridge, UK pp. 33-74, (2000).

[2] Kim JK, Mackay DB and Mai YW, "Drop-weight impact damage tolerance of CFRP with rubber-modified epoxy matrix" Composites, 24, 485-491(1993).

[3] Cantwell WJ and Morton J, "The impact resistance of composite materials-A review" Composites, 22, 347-372 (1991).

[4] Summerscales J, Non-destructive Testing of Fibre-reinforced Plastics Composites, Elsevier Appl. Sci., New York, (1987).

[5] Gao SL and Kim JK, "Scanning acoustic microscopy as a tool for quantitative characterisation of damage in CFRPs" Compos. Sci. Technol. 59, 345-354 (1999).

[6] Hirai $\mathrm{Y}$, Hamada $\mathrm{H}$ and Kim JK, "Impact response of glass woven fabric laminates: part 1. Effect of silane coupling agents" Compos. Sci. Technol. 58, 91-104 (1998).

[7] Hirai $\mathrm{Y}$, Hamada $\mathrm{H}$ and Kim JK, "Impact response of glass woven fabric laminates: part 2. Effect of temperature", Compos. Sci. Technol., 58, 119-128 (1998).

[8] Kortschot MT and Zhang CJ, "Characterization of composite mesostructures and damage by de-ply radiography" Compos. Sci. Technol. 53, 175-181 (1995).

[9] Hopkins PP, Morgan IL, Ellinger H and Klinksiek R, "Tomographic image analysis" Mater. Eval., 40, 1226-1228 (1982).

[10] Bathias C and Cagnasso A, "Application of X-ray tomography to the nondestructive testing of high-performance polymer composites" in ASTM Damage Detection in Composite Materials, ASTM STP 1128, J.E. pp.35-54 (1992).

[11] Mclntire P, ed. Nondestructive Testing Handbook, $2^{\text {nd }}$ edition, Vol. 7, Ultrasonic Testing, American Society for Nondestructive Testing, (1991).

[12] Kim JK, Leung LM, Hirai $Y$ and Lee SWR, "Impact performance of a woven fabric CFRP" Polym. Polym. Composites, 4, 549-561 (1996).

[13] Gao SL and Kim JK, "Three dimensional characterisation of impact damage in CFRPs", Key Eng. Mater. 141-143, 35-54 (1998).

[14] Gao SL and Kim JK, "Cooling rate influences in carbon fibre/PEEK composites, Part III. low-energy impact damage resistance" Compos. Part A. 32, 775-785 (2001).

[15] Kim JK, "Methods for improving impact damage resistance of CFRPs" Key Eng. Mater. 141-143, 149-168 (1998).

[16] Kim JK and Mai YW, in Engineered Interfaces in Fibre Reinforced Composites, Elsevier, New York, Chapter 8, pp. 329-365 (1998).

[17] Todoroki, A, Kobayashi, H and Lee, JG, "Impact analysis of delamination cracks in carbon-fibre composites by scanning acoustic microscopy" Compos. Sci. Technol., 52, 551-559 (1992).

[18] Buynak CF, Moran TJ and Donaldson S, "Characterization of impact damage in composites" SAMPE J., 24, 35-39 (1988). 